\title{
To "MOOC" or Not to "MOOC": Contributors to the Successful Implementation of MOOC in Countries of the GCC
}

\author{
Badr Salman H Alsoliman \\ King Abdulaziz University, College of Educational Graduate Studies, Jeddah, Saudi Arabia \\ E-mail: balsoliman@kau.edu.sa
}

Received: January 15, 2019 Accepted: February 20, 2019 Published: February 22, 2019

doi: 10.5296/ire.v7i1.14235

URL: https://doi.org/10.5296/ire.v7i1.14235

\begin{abstract}
Educational universities of GCC countries have developed a promising implementation of distance learning by delivering complete courses and degrees online. The present study aims to investigate the potentials and barriers for the successful implementation of MOOC in GCC countries. Delphi methods have been employed by recruiting 10 experts for maintaining a feasible and acceptable number of a sample size from different GCC countries. The findings indicated the issues related to a reduction in the fees of MOOCs and improvement in the adaptability of the offered MOOCs. The study pinpointed the instructors' significant role in the provision of user-customized feedback and highlighted the instructors' need for reward and recognition for the needed time and efforts. GCC countries can reap the benefits of MOOCs, if they reshaped their educational policies as a new model of credible learning, leading to employers' recognition to MOOCs certificates.
\end{abstract}

Keywords: MOOC, Distance learning, Educational technology, Online learning, E-Learning

\section{Introduction}

The term MOOC is an acronym for Massive Open Online Course, which reflects the students involved in learning at open courses platform (Downes, 2008). Taneja and Goel (2012) defined MOOC as an online course, which can be attended by many participants at a similar time. The duration of the course is $4-10$ weeks, and it follows certain pedagogy. This definition puts forward a general idea of MOOC and attaches no certain pedagogy to the perspective of MOOC. The advent of educational technology has encouraged the educators' initiatives to utilize such technologies. The trend has started from the use of the internet, with 
further movement to the creation of new perspectives of educating students at a distance, leading to learning in the form of MOOCs. More than 400 global universities and educational institutions have expanded their approach to include Massive Open Online Courses (MOOCs). According to Chauhan (2017), the students' registration has exceeded to 58 million enrolled in more than 700 universities which represent approximately 6850 courses.

Most of the platforms reach Arabic population; therefore, the Arabic language is comprehensively used for such platforms. One such example is Edraak supported by Queen Rania Foundation for Education and Development (QRF) (Ruipérez-Valiente \& Reich, 2018). It offers both English courses, which are translated into the Arabic language utilizing Open edX technology (Adham \& Lundqvist, 2015). Similarly, some local professors present Arabic courses in English to the non-Arab audience. The latest technological advancement in communication and its related technical infrastructures have increased the trend of online teaching. The educational universities/institutions of GCC countries have developed a promising implementation of distance learning in the region by delivering complete courses and degrees online by utilizing the available technological infrastructure. Moreover, there are cultural aspects that are clear, like in An-Najah's MOOC, where the focus is on the Palestine history and archeology (Adham \& Lundqvist, 2015). However, their endeavors in implementing and utilizing MOOC trend are on a halt and facing high dropout rates despite of GCC educational universities' and institutions' efforts and investments in online and distance learning implementation (Greene, Oswald, \& Pomerantz, 2015).

The trend of MOOC has started initially by introducing "Udacity" in Stanford University that attracted the attention of more than 160,000 students from 190 different countries. More Universities around the western world have started to offer many MOOC courses, which resulted in the development of certain opportunities, seized by many Western and Asian countries; GCC in particular (Subbian, 2013).

Two significant types of MOOC have been determined with their merits and significant features. The first category of MOOC is referred as 'cMOOCs' which lends itself to the connectivism theory, where the targeted learners are interested in the distribution of knowledge more than gaining accreditation to the courses they join (Mackness et al., 2013). Moreover, the cMOOCs reflected the concepts of the theories that are present under the umbrella of the connectivism. It advocates the heavy engagement and contribution of the learner as it complies with the creation of knowledge through social networking. Social networking is underpinned by approaches; such as interactive learning, collaborative learning, and practical inquiry (Gaebel, 2013).

XMOOCs courses are developed as the alternative version to the cMOOC's to target learners, who are more interested in accreditation and certified skills (Daniel, 2012). These individuals are not able to attend traditional classes. The xMOOCs is helpful in creating a space for learners to gain an accredited knowledge that reflects the nature of traditional classes without the conventional constraints of time and place. It is based on an online platform that supports the distribution of courses to massive numbers of students with low cost and recognized certification (Downes, 2013). 


\subsection{MOOCs Enablers and Barriers in the GCC}

The utilization of MOOCs in GCC was initiated just after the beginning of MOOCs in the western world (Liyanagunawardena, Adams, \& Williams, 2013). In 2013, Saudi Arabia took the lead in the investment of MOOCs by initiating its first project "Rwaq" to join the global trend of investing in MOOCs (Brahimi \& Sarirete, 2015).

As illustrated in the book of Paulo Friere "Pedagogy of the oppressed" which mentioned that the education can be a step towards liberation and freedom (Freire, 1970). Similarly, Feinberg (1970) has presented a critical theory of technology, which is also focused on developing a relationship between education and technology for getting maximum output. However, there are differences that are present on the basis of culture, religion or social practices in the region in current educational systems (Adham et al., 2018). These should be catered based on the fact that education is a practice that ensures liberty and freedom (Adham et al., 2018).

There is a mismatch between modern and traditional learning, despite incredible advancement in terms of educational facilities in all Gulf monarchies. Moreover, the gap between men and women is quite evident. For so; it is of utmost importance and priority to implement MOOCs in the Arab world (Adham \& Lundqvist, 2015). Along with it, the classrooms are also found to be overcrowded; and due to lack of resources, students are unable to get a quality education. Mainly, in Arabic countries, there are fewer opportunities for females as compared to males and that is the result of gender segregation. It creates a communication gap between males and females, and they cannot communicate freely (Tubaishat et al., 2006). Saudi Arabia of all other countries strictly emphasized "gender segregation". In accordance with that; MOOC launched a platform i.e. open-platform MOOC under the Ministry of Labour, which targeted women especially (Adham \& Lundqvist, 2015). This platform was launched to remove social and cultural limitations. These efforts are viewed in the context of educational borrowing.

The transformation of educational borrowing has helped in the transformation of educational reforms worldwide. Whereas, there is always a possibility that borrowing educational policies may not be effective everywhere (Macleod et al., 2015). In particular, the crosscheck of educational policies is needed to be done for assuring quality education, if the focus is made on Gulf Corporation Council (GCC) countries. Therefore, this study aims to investigate the potentials and barriers to the implementation of MOOC in GCC countries and shed light on the main contributors to the application of MOOC in those countries. The study is expected to draw an outline for future studies in GCC countries that are interested in the utilization of MOOC by identifying positive factors that influence the application of MOOC in the targeted countries. The study is significant as it has investigated the perceptions of Saudi individuals regarding MOOCs that contributes towards the evolution of educational developments in GCC countries to improve the prevailing culture. It would significantly contribute towards improving knowledge, personalities, and educational and professional lives of the individuals depending on their aim and current position. It is likely to provide courses focusing on the education for Saudis to carry out the jobs allocated to the students recently. 


\section{Literature Review}

\subsection{Theoretical Framework - Hofstede's Cultural Dimension Theory}

MOOCs allow to assembling data regarding cross-cultural differences in user behaviors. A lot of research has been done in accordance to examine how the cultural dimensions and values differ across various cultures. In this regard, the most common framework utilized is Hofstede's Cultural Dimension Theory (Liu et al., 2016). In it, Hofstede carried out a survey, and after its assessment he provided different dimensions while explaining the differences in collaboration across different cultures (Mazanec et al., 2015; Zemsky et al., 2005). The dimensions inclusive in the framework include power distance, individualism, creativism, masculinity and feminity, uncertainty avoidance, long-term orientation vs short-term variation, as well as indulgence and restraint. With regard to the cultural dimension, previous studies have reported that the learners' culture affects their learning behavior within the MOOC course. Such as, the application of MOOC has been examined in the quiz-profile activity form considering the Hofstede cultural dimension (Liu et al., 2016). The study showed that cultural variation among the people impacts their learning behavior in the MOOC.

The main aspect of this particular study is on the individualism which instigates the component of cultural dimension practices across the globe (Gelfand et al., 2011). It has also been viewed as the country level dimension by Davis et al (2017). The selection of the particular dimension or model is made in an attempt to study the learner's cultural context that resonated with his learning, to induce in the feedback internationalization as well as stimulates positive behavior. The reason for selection is based on the identification of such dimensions which serve to be effective in executing the MOOC concept in the Arab Region along with its wide acceptance in the diversified conditions that prevail among the GCC countries.

\subsection{Empirical Review}

MOOC has become popular in overseas markets with the passage of time. This gradual enhancement has led some people to view MOOC as an alternative to global expansion (Wilson, \& Gruzd, 2014). MOOCs ensures the availability of users from across the globe, as it is available online. Whereas, MOOC's is also playing a critical role in today's world, where higher education is advancing towards becoming global (Zemsky et al., 2005). Conole (2016) elucidated that the students enrolled in the MOOC course have been found to demonstrate improved educational performance due to the course distinctive features such as its openness and ability to cater several people. Furthermore, the integration of the difficult assessments along with gamification agents makes it more appealing and compelling for the learners (De Freitas, Morgan, \& Gibson, 2015).

The MOOC evaluation has provided a new way to integrate into efforts and understand the difference between the cultures assisting in cultural collaboration (Aguaded-Gómez, 2013). The effectiveness of the MOOC courses was evaluated by Ahn, Yoon, and Cha (2015) among the Korean population. According to the results, the provision of education and assessment in 
it allows students to optimize their learning and advancing their learning abilities. Che et al. (2016) also supplemented the effectiveness of MOOC on the Chinese population assisting in the learning of the students.

The teaching aspects of the MOOC has been evaluated, which have been identified to be related to certain platforms. Such as Li et al. (2015) provides that MOOC platforms' effectiveness is related to catering various features of the learners based on its comprehensive profiling of the students. The course of MOOC is also impacted by its educational orientations such as increased use of videos, and social interaction (Wong, 2015). According to the study of Wong et al. (2015), the offering of the MOOC course serves as the motivation factor for the learners as it is viewed as an advanced tool of learning to improve the performance. Sanchez-Gordon, and Luján-Mora (2016) elucidated that the accessibility to the MOOC program and use of effective design also enhances the academic performance of the learners.

Eisenberg and Fischer (2014) highlighted two main advantages of the MOOC program i.e. cost-effectiveness and feasibility to access it from any place eradicating all time and place constraints which exist in conventional educational practices. The concept of lifelong learning and MOOCs openness to massive numbers of students were also suggested by Jansen, Darco, and Schuwer (2014) to encourage the utilization of MOOCs by many education providers around western countries. Certification of MOOCs is observed as an attracting factor by the learners, especially for those who prefer the xMOOCs model (Gil-Jaurena, Callejo-Gallego, \& Agudo, 2017). Along with it, the study by Urrutia et al. (2015) provides that to meet the social interaction aspect, the integration of the MOOC is adopted as a stimulating factor for many institutes, assisting them in being in-line with the academic evolution. However, there are certain factors that are viewed to impact the effective execution of the MOOC courses. The uncertainty associated with the MOOC courses gives rise to the negative perception of the students as the instructor fail to provide them with the relevant support (Hew \& Cheung, 2014).

The providers of MOOCs in the western world reported many barriers to utilizing complete potentials of MOOCs. Núñez, Caro and González (2017) reported that many providers of MOOCs perceived higher dropout rates and the need for highly technical, monitoring, and funding support. Similarly, Khalil and Ebner (2014) pinpointed instructors' complaints related to lack of time, financial rewards, and consideration to their instructive work. According to the study, the engagement level of instructor with massive numbers of students declined with the integration of MOOC programs, negatively impacting the learning of the students as they require instant feedback, engagement, evaluation, and consideration of different learning styles. These needs have been cited by many studies such as Najafi et al. (2015) which provides that the feeling of isolation, lack of support, and need of more engagement serves as a barrier for deliverance of meaningful learning experience in MOOC. Moreover, barriers related to lack of motivation and autonomy of learners are also attached to MOOCs trends that are more or less a repercussion of providers' inability to overcome the main barriers. 
Many obstacles have been faced by the expansion of such trend; although, the utilization of MOOCs in GCC was encouraged by many enablers. The investment of MOOCs in GCC was very promising. MOOC enablers in the GCC countries went beyond the financial and technical aspects that were related to the nature of population and beliefs (Brahimi \& Sarirete, 2015). GCC countries have major requirements of financial and technical aspects, which can be deemed as enablers for the implementation of MOOCs (Al-Maamary, Kazem, \& Chaichan, 2016). In addition, gender separation is preferred according to the tradition and beliefs in GCC countries. On the other hand, MOOCs in the GCC countries undergoes higher pressure as compared to the western world as it suffers from the similar barriers related to language, quality, and policies (Badry \& Willoughby, 2015). Many global MOOCs does not support the Arabic language, which deprives GCC learners of the participation and active engagement in learning activities (Barak, Watted, \& Haick, 2016). In addition, MOOCs models in the GCC countries do not tie themselves to the organized and recognized e-learning and distance learning that is provided by GCC universities. Therefore, it suffers the lack of quality monitoring and solid policies that support the engagement in the different MOOCs available in the GCC countries.

Furthermore, the research illustrated that usually there are four reasons why students sign up for MOOCs (DeBoer et al., 2013). Some of them are just curious about MOOCs, while others fulfill their desire to learn and enhance their knowledge and lastly, there are those people, who desire to collect completion certificates (García-Peñalvo et al., 2015). Not many people are not able to complete their course; though, the enrolment is done in millions. The reason behind this case is usually that the pupils' lack incentive or they fail to understand the content of the given material. However, there are certain challenges in terms of teaching MOOCs. Firstly, it is not possible to keep a check on the student's performance and working status. Secondly, the feedback system is rigorously weak. Furthermore, there is always a burden of time and money for the participants (Parrish \& Linder-VanBerschot, 2010)). Taking care of all such challenges would definitely result in the better development of MOOC.

The study reviewed the literature, related to the application of MOOC globally and in GCC countries to compare and contrast between the potentials and the expected barriers to the utilization of MOOC internationally; and particularly in western Asia. Furthermore, Delphi survey has been carried out with experts in the field to explore the contributing factors to successfully and efficiently apply MOOC. The selection of the particular method is based on the findings of the earlier researches. Such as according to the study of Kovanović et al. (2015), the concept of MOOC is gaining considerable attention in both press popularity aspect as well as an area of academic research. However, there are certain lacking observed. Liyanagunawardena et al. (2013) study supplements that, despite the increase in the MOOC, its experience in the developing regions remains low. Similarly, another study by Raffaghelli, Cucchiara, and Persico (2015) on MOOC illustrated that the case study approach is commonly adopted for MOOC evaluation.

\subsection{Research Objectives}

- To predict contributors for successful implementation of MOOCs in the GCC countries. 


\section{Macrothink}

- To elucidate the factors which impact the successful implementation of MOOCs in the GCC countries.

- To foresee GCC countries' ability to fulfil those contributors.

\section{Material and Methods}

\subsection{Research Design}

The study has used the Delphi method to achieve its main objectives as it has provided a successful method of predicting future trends in the field of e-learning and distance learning (Kalaian \& Kasim, 2012).

\subsection{Study Sample}

The study has recruited 10 experts ( 7 males and 3 females) to maintain a feasible and acceptable number of a sample size from different GCC countries to accomplish the study variation (Hsu and Sanford, 2007). The choice of experts was not arbitrary as shown by Giannarou and Zervas (Ginnarou \& Zervas, 2014). Eventually, the experts' panel were 10 experts from all GCC countries except Qatar, which may have a limited effect on the findings. Two experts of each GCC country have participated in the survey and no drop out occurred (i.e. Saudi Arabia, Kuwait, Oman, Bahrain, and UAE). Experts have fulfilled the requirement of the study as each of them was working in the online learning industry, held a degree related to online or e-learning, spent at least five years in a leading position in the field of online learning, and has a recognized contribution in the field.

\subsection{Data Collection}

The Delphi method was conducted in two phases; in the first phase, experts were asked to list contributors to a successful MOOC in the GCC countries. In the second phase of Delphi survey experts' panel rated the list created in the first phase according to seven Likert scale ratings . The study used three-rounds-questionnaire in the second phase based on 7-point Likert scale ratings suggested by Vagias and Wade (2006); where 1 = "strongly agree", 2 = "agree", 3 = "somewhat agree", 4 = "neither agree nor disagree", 5 = "somewhat disagree", 6 $=$ "disagree" and $7=$ "strongly disagree".

\subsection{Data Assessment}

Subsequent to the data collection, the responses of the experts were analyzed using SPSS version 22.0. The data was statistically assessed and illustrated in the graphical form assisting readers in its comprehensive evaluation.

\section{Results}

\subsection{First Phase}

In the first round of Delphi survey, the experts were asked to list contributors to a successful MOOC in the GCC countries. The listed contributors/items were thematically categorized into six categories (i.e. cost, credibility, language, accessibility, employability, and instruction) which are mainly deduced from the literature, where similar items in the expert's lists (share 
the same idea) were merged into one item that reflected the main contributor (Badry \& Willoughby, 2015; Ahn, Yoon, \& Cha, 2015; Sanchez-Gordon \& Luján-Mora, 2016). The final list was comprised of 32 items, presented in Table 1 to 5. Table 1 has provided the cost serves as the main stimulator for the effective implementation of the MOOC courses such as the no charge of fees promotes the individual's adaptation of the course.

Table 1. First-round list of experts' panel of contributors considering cost (in the first round of the Delphi survey)

\begin{tabular}{ll}
\hline $\mathrm{N}$ & Contributors \\
\hline & Cost \\
1 & Significantly low or no fees for MOOCs access \\
2 & Significantly low or no fees for MOOC certification \\
3 & $\begin{array}{l}\text { MOOCs must be designed for regular alteration and easy rescheduling to fit the } \\
\text { consumers' needs and reduce cost }\end{array}$ \\
\hline
\end{tabular}

In Table 2, the experts have provided that following cost, credibility is another factor in which the institute offering the MOOC is viewed to play a critical role. Along with it, provision of specialized packages of MOOCs, valid assessment procedure, intellectual property security, and well-developed platform also impact the MOOC courses implementation across GCC.

Table 2. First-round list of experts' panel of contributors considering credibility (in the first round of the Delphi survey)

\begin{tabular}{ll}
\hline $\mathrm{N}$ & Contribution \\
\hline & $\begin{array}{l}\text { Credibility } \\
\text { MOOCs' credits are recognized by traditional universities/institutions in the GCC } \\
5\end{array}$ \\
& $\begin{array}{l}\text { The provision of specialized packages of MOOCs in particular fields of study that can } \\
\text { lead to a recognized degree, certificate or diploma }\end{array}$ \\
6 & $\begin{array}{l}\text { Authentication procedures for validating students in MOOCs assessment are clear and } \\
\text { credible (for certification purpose) }\end{array}$ \\
7 & $\begin{array}{l}\text { The protection of the intellectual property of any development concerning of MOOCs' } \\
\text { tools, technology, and content. }\end{array}$ \\
8 & $\begin{array}{l}\text { All GCC MOOCs platforms must be hosted and developed by one highly recognized } \\
\text { technological provider (i.e. Google, Amazon...) }\end{array}$ \\
9 & MOOCs quality must be monitored by one GCC recognized body. \\
10 & MOOCs assessment methods must be unified amongst GCC
\end{tabular}


Experts' panel of contributors ranks language as another theme, where the effort is on supplementing the Arabic translation and interface as illustrated in Table 3.

Table 3. First-round list of experts' panel of contributors considering language (in the first round of the Delphi survey)

\begin{tabular}{ll}
\hline & Language \\
\hline 11 & All MOOCs content is translated into Arabic unless other languages are necessary \\
12 & The use of an Arabic interface \\
\hline
\end{tabular}

Accessibility is recognized as another theme, which ranks at the 4 levels of the MOOC implementation. Designing, cost, tools, access, integrated database, and provision to the diverse segment are found to impact the execution of the MOOC in the region. Additionally, users' system and assimilation of the MOOC platform is also recognized in it by the experts as indicated in Table 4.

Table 4. First-round list of experts' panel of contributors considering accessibility (in the first round of the Delphi survey)

\begin{tabular}{ll}
\hline & Accessibility \\
\hline 13 & The provision of an actually designated rendezvous \\
14 & Low cost and reliable internet connection \\
15 & MOOCs platform is open for new development in content, tools, and use of technology \\
16 & Accessibility to MOOCs on multiple access platforms (i.e. computers, Android, iOS) \\
17 & The availability of GCC integrated database for the offered MOOCs \\
18 & MOOCs must cater to all segments of society with no age limitation \\
19 & Users system/status check for connection and availability for MOOCs requirement before \\
& registration \\
20 & The used of unified MOOCs platform for all GCC countries \\
\hline
\end{tabular}

In the employability theme, the experts' listed employers accessibility at 21 , followed by collaboration, indulgence in training courses, as well as certification. All these have been listed from 21 to 24 place as represented in Table 5.

Table 5. First-round list of experts' panel of contributors considering employability (in the first round of the Delphi survey)

\begin{tabular}{ll}
\hline & Employability \\
\hline 21 & Employers accessibility to MOOCs learners' database \\
22 & Effective collaboration with employers in the private/public sectors in subject and content \\
& development
\end{tabular}


23 MOOCs in GCC countries must cover: training courses, academic and non-academic

24 MOOCs' certificate is recognized by public/private employers in the GCC countries

Table 6 has represented the listing of the experts in the context of MOOC instruction. According to them, the theme has the lowest impact based on the listing of the factors which fall in this category. Where, instruction tools for discussion rest top, followed by its customization, MOOCs duration verity, methods, leading to a difference in content type.

Table 6. First-round list of experts' panel of contributors considering instructions (in the first round of the Delphi survey)

\begin{tabular}{ll}
\hline & Instruction \\
\hline 25 & The availability of diverse collaboration and discussion tools \\
26 & The provision of user-customized assistance (no automated feedback) \\
27 & The provision of the verity of MOOCs duration \\
28 & The availability of a variety of methods of instruction, engagement, and technology \\
29 & Recognition and reward for instructors' time and high engagement \\
30 & GCC standardized and required level of MOOCs' instructors' competency \\
31 & MOOCs assessment methods must not depend on logins solely on files and take into \\
& account engagement in collaborative activities and exams \\
32 & The availability of diverse types of content materials (i.e. eBooks, websites, \\
presentations...)
\end{tabular}

\subsection{Second Phase}

The second phase of the Delphi survey required the experts' panel to rate the list created in the first phase according to seven Likert scale ratings suggested by Vagias and Wade (2006). The study used steps suggested by Kalaian and Kasim (2012) and computed the median and interquartile to determine the consensus on agreement or disagreement from the panel of experts regarding the survey items. The survey runs for three rounds; at the first round, the survey was sent to the experts to rate all the 32 items according to 7 Likert scale ratings. The IQR and median were computed for each item. The survey was sent again to the experts to change their rating if possible, to concur with the group responses and reflect on their ration. Finally, in the third round, the expert's previous rating, IQR, and the median of the group in the first and second rounds were visible to the experts. Items that reached consensus in each round are presented in Table 7, 8, and 9 respectively.

According to the contributors, the low or no fee of the MOOC certification serves as the effective implementation tool along with its flexibility of rescheduling as per the user need and economic stance as illustrated in Table 7. The amalgamation of the different agent's part of the six themes is observed evident from the listing of the content in Table 7, 8, and 9. 
Table 7. Contributors that achieved consensus on the agreement in the first round of the Delphi survey

\begin{tabular}{|c|c|c|c|}
\hline No & Contributors & Median & IQR \\
\hline 2 & $\begin{array}{l}\text { Significantly low or no fees for MOOC certification compared to } \\
\text { traditional learning }\end{array}$ & 1.50 & 1.00 \\
\hline 3 & $\begin{array}{l}\text { MOOCs are designed for regular alteration and easy rescheduling } \\
\text { to fit the consumers' needs and reduce cost }\end{array}$ & 2.00 & 1.25 \\
\hline 4 & $\begin{array}{l}\text { MOOCs' credits are recognized by traditional } \\
\text { universities/institutions in the GCC countries }\end{array}$ & 2.00 & 1.25 \\
\hline 5 & $\begin{array}{l}\text { The provision of specialized packages of MOOCs in particular } \\
\text { fields of study that can lead to a recognized degree, certificate or } \\
\text { diploma }\end{array}$ & 2.00 & 1.25 \\
\hline 6 & $\begin{array}{l}\text { Authentication procedures for validating students in MOOCs } \\
\text { assessment are clear and credible (for certification purpose) }\end{array}$ & 2.00 & 1.50 \\
\hline 24 & $\begin{array}{l}\text { MOOCs' certificate is recognized by public/private employers in } \\
\text { the GCC countries }\end{array}$ & 2.00 & 1.25 \\
\hline 11 & $\begin{array}{l}\text { All MOOCs content is in Arabic or translated into Arabic unless } \\
\text { other languages are necessary }\end{array}$ & 1.50 & 1.00 \\
\hline 12 & The use of an Arabic interface & 1.50 & 1.00 \\
\hline 14 & Low cost and reliable internet connection & 1.50 & 1.00 \\
\hline 15 & $\begin{array}{l}\text { MOOCs platform is open for new development in content, tools, } \\
\text { and use of technology }\end{array}$ & 2.00 & 1.00 \\
\hline 16 & $\begin{array}{l}\text { Accessibility to MOOCs on multiple access platforms (i.e. } \\
\text { computers, Android, iOS) }\end{array}$ & 1.50 & 1.25 \\
\hline 17 & $\begin{array}{l}\text { The availability of GCC integrated database for the offered } \\
\text { MOOCs }\end{array}$ & 1.50 & 1.00 \\
\hline 28 & $\begin{array}{l}\text { The availability of a variety of methods of instruction, } \\
\text { engagement, and technology }\end{array}$ & 2.00 & 0.25 \\
\hline 19 & $\begin{array}{l}\text { Users system/status check for connection and availability for } \\
\text { MOOCs requirement before registration }\end{array}$ & 2.00 & 1.25 \\
\hline 20 & The used of unified MOOCs platform for all GCC countries & 2.00 & 1.25 \\
\hline
\end{tabular}

Table 8. Contributors that achieved consensus on the agreement in the second round of the Delphi survey

\begin{tabular}{lllc}
\hline No & Contributors & Median & IQR \\
\hline 21 & Employers accessibility to MOOCs learners' database & 1.50 & 1.00 \\
22 & $\begin{array}{l}\text { Effective collaboration with employers in the private/public sectors } \\
\text { in subject and content development }\end{array}$ & 2.00 & 1.25 \\
29 & $\begin{array}{l}\text { Recognition and reward for instructors' time and high engagement } \\
30\end{array}$ & $\begin{array}{l}\text { GCC standardized and required level of MOOCs' instructors' } \\
\text { competency }\end{array}$ & 2.00 \\
\hline
\end{tabular}


Table 9. Contributors that achieved consensus on the agreement in the third round of the Delphi survey

\begin{tabular}{lllll}
\hline No & Statement (proposed solution) & Median & IQR \\
\hline 26 & $\begin{array}{l}\text { The provision of user-customized assistance (no automated } \\
\text { feedback) }\end{array}$ & 2.00 & 1.25 \\
32 & $\begin{array}{l}\text { The availability of diverse types of learning materials (i.e. eBooks, } \\
\text { websites, presentations...) }\end{array}$ & 1.00 \\
\hline
\end{tabular}

\section{Discussion}

The results of the study highlight the offering of cost-effective programs and courses for the students as per the expert listing. These are in-line with the previous study findings of Mazoue (2014) which studied the challenges of the academics. The execution of the cost-effective MOOC courses enhances students' learning as compared to the conventional ways. Furthermore, the findings indicated that more attractive designs for learners and institutions, issues related to reducing the fees of MOOCs certificates, and improving the adaptability of the offered MOOCs must be considered while making MOOCs in the GCC countries. These findings are in accordance with Baturay (2015), which indicated that MOOCs can save the production cost that may burden the institutions budget. Along with it, Conole (2015) also endorses the study finding emphasizing on the integration of the effective MOOC design. The MOOC certification has been also recognized by Conole (2016) which examined the strategies which can improve the effectiveness of the MOOC programs.

In conjunction with this, contributors of successful MOOCs in GCC concurred with the finding of Wang, Wen and Rosé (2016) that suggested the need for authentic assessment for the MOOCs' learners. Other vital contributors to reap the full potential of MOOCs in the GCC countries were directed to the job markets, where the cooperation between employers (private or public) must play a role in recognizing MOOCs learners' outcomes. It cannot be achieved unless active cooperation between the MOOCs providers (i.e. companies, agencies, institutions, universities (Baturay, 2015). Moreover, the technological requirements were similar to previous studies (Wang et al., 2016; Barnett, 2015). The findings showed that the foreseen contributors of successful MOOCs were more focused on the building between the provider and the recipient. This association tends to stress the availability of multiple accesses platforms, reliable connection, flexibility to changes, and integrated and reliable MOOCs system for all GCC countries.

The study pinpointed the instructors' significant role in the provision of user-customized feedback and instructional methods and highlighted the instructors' need for reward and recognition for the needed time and efforts. It was underpinned by Hew (2016) as a requirement in any e-learning system, who also suggested an accepted level of instructors' competency in technological methods of instruction. Furthermore, contributors in the GCC countries highlighted another important dimension related to the language used in the MOOCs for non-English speakers, who were listed as a concern by Godwin-Jones (2014). The language issue is also related to the difference in culture, which impacts the efficiency of 
the MOOC program for the learner (Barak, Watted, \& Haick, 2016). However, the focus of contributors to GCC MOOCs was on the use of the Arabic language as the main interface and content language.

The study has revealed many contributors to the successful implementation of MOOCs in the GCC countries that covered six main dimensions (cost, credibility, language, accessibility, employability, and instruction). Contributors to the cost, accessibility, and instruction dimensions were not hard to achieve given the financial and technological resources available for the GCC countries (Al-Maamary et al., 2016; Elmawazini, 2014). However, contributors related to the language, employability, and credibility faced many challenges, beginning from the GCC current educational policies that do not recognize the credibility of MOOCs (Jemni and Khribi, 2017). It has its negative influence on the employability of MOOCs finishers that struggle to find a job that recognizes their MOOCs certificates (Jemni \& Khribi, 2017). Moreover, the shortage of Arabic MOOCs in GCC countries has its implication on the attractiveness of MOOCs in GCC.

The present study has shown that majority of the recruited individuals showed significant interest in attaining the skills that are effective in improving the professional knowledge and performance. This result has been supported by the studies conducted by Vivian et al. (2014) and Lim et al. (2017). Another recent study conducted by Davies (2017) revealed that contemporary lure of the shiny gadgets motivates the level of participation among the individuals as they tend to access new resources. However, the context of present study is based on the recent forms of online learning that is MOOC. Majority of the learners are attracted towards this platform because of the pre-existing attraction attained using this particular technology (Davies, 2017). A study conducted by Guirdham and Guirdham (2017) stated that it is possible to identify the similar values at individual and country levels by using the social level data. The contributions and collaboration of the participants in the community of MOOCs and within social media assist in the origin of primary source of feedback for MOOC participants (Kasch et al., 2017).

\section{Conclusion}

The present study evaluated the contribution of the various factors for the effective implementation of MOOC in countries of the GCC. For this, the study covered six main dimensions (i.e. cost, credibility, language, accessibility, employability, and instruction). Based on the findings, the study reveals that cost-effectiveness of the MOOC program serves as the prime factor for the successful implementation of MOOC. Along with it, the design and accessibility also serve as great stimulator for its effectiveness. The study concludes that all these components must be instigated together for deliverance of the meaningful learning experience, necessary for the MOOC systems success.

The GCC countries can reap the benefits of MOOCs, only if they have reshaped their educational policies to encompass MOOCs as a new model of credible learning, which can lead to employers' recognition to MOOCs certificates. It is expected to give rise to a rapid generation of Arabic MOOCs, pushed by the attractiveness of the MOOCs in the GCC as a result of MOOCs recognition. Based on the findings, the study suggests for making effort for 
ensuring complete participation of all the MOOC agents involving learners as well as instructors. Efforts must be made for the training and supplementing of helpful material for integrating effective pedagogical approaches ensuring optimal satisfaction for MOOC learners. The limitations of the study include its small sample size, and confinement to a particular region, which hinder its generalizability of the study results. Future researches can investigate the disciplinary representation in the MOOC for expanding the existing knowledge of MOOC.

\section{Acknowledgement}

The author is very thankful to all the associated personnel in any reference that contributed in/for the purpose of this research. Further, the study is not funded by any source and declares no conflict interest.

\section{References}

Adham, R. S., \& Lundqvist, K. O. (2015). MOOCs as a method of distance education in the Arab world-A review paper. European Journal of Open, Distance and E-learning, 18(1), 123-138. https://doi.org/10.1515/eurodl-2015-0009

Adham, R., Parslow, P., Dimitriadi, Y., \& Lundqvist, K. Ø. (2018). The: Use of Avatars in Gender Segregated Online Learning Within MOOCs in Saudi Arabia-A Rwaq Case Study. The International Review of Research in Open and Distributed Learning, 19(1). https://doi.org/10.19173/irrodl.v19i1.3139

Aguaded-Gómez, J. I. (2013). The MOOC Revolution: A new form of education from the technological paradigm? /La revolución MOOCs, ¿ una nueva educación desde el paradigma tecnológico? Comunicar, 21(41), 7. https://doi.org/10.3916/C41-2013-a1

Ahn, M. L., Yoon, H., \& Cha, H. (2015). Cultural sensitivity and design implications of MOOCs from Korean learners' perspectives: Case studies on edX and Coursera. Educational Technology International, 16(2), 201-229.

Al-Maamary, H. M., Kazem, H. A., \& Chaichan, M. T. (2016). Changing the energy profile of the GCC States: A review. International Journal of Applied Engineering Research (IJAER), 11(3), 1980-1988.

Alshahrani, K., \& Ally, M. (2016). MOOC in the Arab world: a case study. In Transforming Education in the Gulf Region. Routledge. https://doi.org/10.4324/9781315621586

Badry, F., \& Willoughby, J. (2015). Higher education revolutions in the Gulf: Globalization and institutional viability. Routledge. https://doi.org/10.4324/9780203796139

Barak, M., Watted, A., \& Haick, H. (2016). Motivation to learn in massive open online courses: Examining aspects of language and social engagement. Computers \& Education, 94, 49-60. https://doi.org/10.1016/j.compedu.2015.11.010

Barnett, M. R. (2015). The politics of cultural nationalism in South India. Princeton University Press. https://doi.org/10.1515/9781400867189 


\section{Macrothink Institute ${ }^{\mathrm{TM}}$}

Baturay, M. H. (2015). An overview of the world of MOOCs. Procedia-Social and Behavioral Sciences, 174, 427-433. https://doi.org/10.1016/j.sbspro.2015.01.685

Brahimi, T., \& Sarirete, A. (2015). Learning outside the classroom through MOOCs. Computers in Human Behavior, 51, 604-609. https://doi.org/10.1016/j.chb.2015.03.013

Chauhan, J. (2017). An Overview of MOOC in India. International Journal of Computer Trends and Technology, 49(2). https://doi.org/10.14445/22312803/IJCTT-V49P117

Che, X., Luo, S., Wang, C., \& Meinel, C. (2016). An attempt at mooc localization for chinese-speaking users. International Journal of Information and Education Technology, 6(2), 90. https://doi.org/10.7763/IJIET.2016.V6.665

Conole, G. (2015). Designing effective MOOCs. Educational Media International, 52(4), 239-252. https://doi.org/10.1080/09523987.2015.1125989

Conole, G. (2016). MOOCs as disruptive technologies: strategies for enhancing the learner experience and quality of MOOCs. RED: Revista de Educacion a Distancia, 50, 1-18. https://doi.org/10.6018/red/50/2

Daniel, J. (2012). Making sense of MOOCs: Musings in a maze of myth, paradox, and possibility. Journal of Interactive Media in Education, 2012(3). https://doi.org/10.5334/2012-18

Davies, J., \& Graff, M. (2005). Performance in e-learning: online participation and student grades. British Journal of Educational Technology, 36(4), 657-663. https://doi.org/10.1111/j.1467-8535.2005.00542.x

Davis, D., Jivet, I., Kizilcec, R. F., Chen, G., Hauff, C., \& Houben, G. J. (2017, March). Follow the successful crowd: raising MOOC completion rates through social comparison at scale. In Proceedings of the Seventh International Learning Analytics \& Knowledge Conference (pp. 454-463). ACM. https://doi.org/10.1145/3027385.3027411

De Freitas, S. I., Morgan, J., \& Gibson, D. (2015). Will MOOCs transform learning and teaching in higher education? Engagement and course retention in online learning provision. British Journal of Educational Technology, 46(3), 455-471. https://doi.org/10.1111/bjet.12268

DeBoer, J., Stump, G. S., Seaton, D., \& Breslow, L. (2013, June). Diversity in MOOC students' backgrounds and behaviors in relationship to performance in $6.002 \mathrm{x}$. In Proceedings of the Sixth Learning International Networks Consortium Conference (Vol. 4, pp. 16-19).

Downes, S. (2008). MOOC and mookies: The connectivism \& connective knowledge online course. EFest by Ellumninate, Aukland, New Zealand.

Downes, S. (2013). MOOC-the resurgence of community in online learning. Transcript of presentation. May, 30(2013), 5-6.

Eisenberg, M., \& Fischer, G. (2014). MOOCs: A perspective from the learning sciences. In 
Learning and Becoming in Practice: 11th International Conference of the Learning Sciences (ICLS) (pp. 190-197).

Elmawazini, K. (2014). FDI spillovers, efficiency change, and host country labor productivity: evidence from GCC countries. Atlantic Economic Journal, 42(4), 399-411. https://doi.org/10.1007/s11293-014-9428-0

Feinberg, J. (1970). Doing \& deserving; essays in the theory of responsibility.

Freire, P. (1970). Pedagogy of the Oppressed (New York. Continuum, 72.

Gaebel, M. (2013). MOOCs Massive open online courses. EUA Occasional papers.

García-Peñalvo, F. J., Cruz-Benito, J., Borrás-Gené, O., \& Blanco, Á. F. (2015). Evolution of the Conversation and Knowledge Acquisition in Social Networks related to a MOOC Course. In Learning and collaboration technologies (pp. 470-481). Springer, Cham. https://doi.org/10.1007/978-3-319-20609-7_44

Gelfand, M. J., Raver, J. L., Nishii, L., Leslie, L. M., Lun, J., Lim, B. C., \& Aycan, Z. (2011). Differences between tight and loose cultures: A 33-nation study. Science, 332(6033), 1100-1104.

Giannarou, L., \& Zervas, E. (2014). Using Delphi technique to build consensus in practice. International Journal of Business Science and Applied Management, 9(2), 65-82.

Gil-Jaurena, I., Callejo-Gallego, J., \& Agudo, Y. (2017). Evaluation of the UNED MOOCs implementation: demographics, learners' opinions and completion rates. International Review of Research in Open and Distributed Learning, 18(7).

Godwin-Jones, R. (2014). Emerging technologies games in language learning: opportunities and challenges. Language Learning \& Technology, 18(2), 9-19.

Greene, J. A., Oswald, C. A., \& Pomerantz, J. (2015). Predictors of retention and achievement in a massive open online course. American Educational Research Journal, 52(5), 925-955. https://doi.org/10.3102/0002831215584621

Guirdham, M. (2011). Communicating across cultures at work. Macnillan International Higher Education. https://doi.org/10.1007/978-0-230-34471-6

Hew, K. F. (2016). Promoting engagement in online courses: What strategies can we learn from three highly rated MOOCS? British Journal of Educational Technology, 47(2), 320-341. https://doi.org/10.1111/bjet.12235

Hew, K. F., \& Cheung, W. S. (2014). Students' and instructors' use of massive open online courses (MOOCs): Motivations and challenges. Educational research review, 12, 45-58. https://doi.org/10.1016/j.edurev.2014.05.001

Hsu, C. C., \& Sandford, B. A. (2007). The Delphi technique: making sense of consensus. Practical assessment, research \& evaluation, 12(10), 1-8.

Jansen, D., \& Schuwer, R. (2015). Institutional MOOC strategies in Europe. Status Report 
Based on a Mapping Survey Conducted in October-December 2014. Mimeo.

Jemni, M., \& Khribi, M. K. (2017). The ALECSO smart learning framework. In Innovations in smart Learning (pp. 91-101). Springer, Singapore. https://doi.org/10.1007/978-981-10-2419-1_14

Kalaian, S. A., \& Kasim, R. M. (2012). Terminating sequential Delphi survey data collection. Practical Assessment, Research \& Evaluation, 17(5).

Kasch, J., Van Rosmalen, P., \& Kalz, M. (2017). A framework towards educational scalability of open online courses.

Khalil, H., \& Ebner, M. (2014, June). MOOCs completion rates and possible methods to improve retention-A literature review. In EdMedia: World Conference on Educational Media and Technology (pp. 1305-1313). Association for the Advancement of Computing in Education (AACE).

Kinser, K. (2006). From Main Street to Wall Street: For-Profit Higher Education: ASHE Higher Education Report (Vol. 110). Jossey-Bass.

Kovanović, V., Joksimović, S., Gašević, D., Siemens, G., \& Hatala, M. (2015). What public media reveals about MOOC s: A systematic analysis of news reports. British Journal of Educational Technology, 46(3), 510-527. https://doi.org/10.1111/bjet.12277

LeCounte, J. F., \& Johnson, D. (2017). The MOOCs: Characteristics, Benefits, and Challenges to Both Industry and Higher Education. In Blended Learning: Concepts, Methodologies, Tools, and Applications (pp. 2105-2125). IGI Global.

Li, K. C., Wong, B. T., Chok, E. W., \& Lee, T. (2015). Profiling MOOC platforms: Uniformity and diversity in course provision. Studies and Practices for Advancement in Open and Distance Education, 140.

Lim, V., Wee, L., Teo, J., \& Ng, S. (2017). Massive Open and Online Courses and Open Education Resources in Singapore. arXiv preprint arXiv:1708.08743.

Littlejohn, A., Hood, N., Milligan, C., \& Mustain, P. (2016). Learning in MOOCs: Motivations and self-regulated learning in MOOCs. The Internet and Higher Education, 29, 40-48. https://doi.org/10.1016/j.iheduc.2015.12.003

Liu, Z., Brown, R., Lynch, C., Barnes, T., Baker, R. S., Bergner, Y., \& McNamara, D. S. (2016). MOOC Learner Behaviors by Country and Culture; an Exploratory Analysis. EDM, $16,127-134$.

Liyanagunawardena, T. R., Adams, A. A., \& Williams, S. A. (2013). MOOCs: A systematic study of the published literature 2008-2012. The International Review of Research in Open and Distributed Learning, 14(3), 202-227. https://doi.org/10.19173/irrodl.v14i3.1455

Mackness, J., Waite, M., Roberts, G., \& Lovegrove, E. (2013). Learning in a small, taskoriented, connectivist MOOC: Pedagogical issues and implications for higher education. The international review of research in open and distributed learning, 14(4). 
https://doi.org/10.19173/irrodl.v14i4.1548

Macleod, H., Haywood, J., Woodgate, A., \& Alkhatnai, M. (2015). Emerging patterns in MOOCs: Learners, course designs and directions. TechTrends, 59(1), 56-63. https://doi.org/10.1007/s11528-014-0821-y

Mazanec, J. A., Crotts, J. C., Gursoy, D., \& Lu, L. (2015). Homogeneity versus heterogeneity of cultural values: An item-response theoretical approach applying Hofstede's cultural dimensions in a single nation. Tourism Management, 48, 299-304. https://doi.org/10.1016/j.tourman.2014.11.011

Mazoue, J. G. (2014). The MOOC model: Challenging traditional education.

Ming Wong, B. T. (2015). Pedagogic orientations of MOOC platforms: influence on course delivery. Asian Association of Open Universities Journal, 10(2), 49-66. https://doi.org/10.1108/AAOUJ-10-02-2015-B005

Najafi, H., Rolheiser, C., Harrison, L., \& Håklev, S. (2015). University of Toronto instructors' experiences with developing MOOCs. The International Review of Research in Open and Distributed Learning, 16(3). https://doi.org/10.19173/irrodl.v16i3.2073

Nelson, C., \& Grossberg, L. (Eds.). (1988). Marxism and the Interpretation of Culture. University of Illinois Press. https://doi.org/10.1007/978-1-349-19059-1

Núñez, J. L. M., Caro, E. T., \& González, J. R. H. (2017). From higher education to open education: challenges in the transformation of an online traditional course. IEEE Transactions on Education, 60(2), 134-142. https://doi.org/10.1109/TE.2016.2607693

Parrish, P., \& Linder-VanBerschot, J. (2010). Cultural dimensions of learning: Addressing the challenges of multicultural instruction. The International Review of Research in Open and Distributed Learning, 11(2), 1-19. https://doi.org/10.19173/irrodl.v11i2.809

Raffaghelli, J. E., Cucchiara, S., \& Persico, D. (2015). Methodological approaches in MOOC research: Retracing the myth of P roteus. British Journal of Educational Technology, 46(3), 488-509. https://doi.org/10.1111/bjet.12279

Ruipérez-Valiente, J. A., \& Reich, J. (2018, September). Participation of the Arab World in MOOCs. In 2018 Learning with MOOCS (LWMOOCS) (pp. 47-50). IEEE.

Sanchez-Gordon, S., \& Luján-Mora, S. (2016). Design, implementation and evaluation of MOOCs to improve inclusion of diverse learners. In User-centered design strategies for massive open online courses (MOOCs) (pp. 115-141). IGI Global. https://doi.org/10.4018/978-1-4666-9743-0.ch008

Subbian, V. (2013). Role of MOOCs in integrated STEM education: A learning perspective. In Integrated STEM Education Conference (ISEC), 2013 IEEE (pp. 1-4). IEEE. https://doi.org/10.1109/ISECon.2013.6525230

Taneja, S., \& Goel, A. (2014). MOOC providers and their strategies. International Journal of Computer Science and Mobile Computing, 3(5), 222-228. 


\section{Macrothink}

International Research in Education

ISSN 2327-5499

2019, Vol. 7, No. 1

Tubaishat, A., Bhatti, A., \& El-Qawasmeh, E. (2006). ICT experiences in two different Middle Eastern universities. Issues in Informing Science \& Information Technology, 3. https://doi.org/10.28945/922

Urrutia, M. L., White, S., \& White, S. (2015, May). MOOCs in Higher Education magazines: a content analysis of internal stakeholder perspectives. In International Conference on Computer Supported Education (pp. 395-405). Springer, Cham.

Vagias, W. M. (2006). Likert-type Scale Response Anchors. Clemson International Institute for Tourism. \& Research Development, Department of Parks, Recreation and Tourism Management, Clemson University.

Vivian, R., Falkner, K., \& Falkner, N. (2014). Addressing the challenges of a new digital technologies curriculum: MOOCs as a scalable solution for teacher professional development.

Wang, X., Wen, M., \& Rosé, C. P. (2016, April). Towards triggering higher-order thinking behaviors in MOOCs. In Proceedings of the Sixth International Conference on Learning Analytics \& Knowledge (pp. 398-407). ACM. https://doi.org/10.1145/2883851.2883964

Wilson, L., \& Gruzd, A. (2014). MOOCs-international information and education phenomenon? Bulletin of the Association for Information Science and Technology, 40(5), 35-40. https://doi.org/10.1002/bult.2014.1720400510

Wong, B. T., Li, K. C., \& Lam, H. (2015). Motivations and deterrents to MOOC offerings. Studies and Practices for Advancement in Open and Distance Education, 16.

Zemsky, R., Wegner, G. R., \& Massy, W. F. (2005). Remaking the American university: Market-smart and mission-centered. Rutgers University Press.

\section{Copyright Disclaimer}

Copyright reserved by the authors.

This article is an open-access article distributed under the terms and conditions of the Creative Commons Attribution license (http://creativecommons.org/licenses/by/3.0/). 